\title{
A INFLUÊNCIA DA IGREJA CATÓLICA NO CAMPO EDUCACIONAL DO MUNICÍPIO DE CRUZEIRO DO SUL/ACRE: REFLEXÕES SOBRE A INTERAÇÃO ENTRE O PÚBLICO E O PRIVADO
}

\author{
MARIA IRINILDA DA SILVA BEZERRA \\ GIANE LUCÉlIA Grott \\ Universidade Federal do Acre (UFAC), Rio Branco, Acre, Brasil
}

\begin{abstract}
Resumo: Este estudo tem como objetivo discutir a influência da Igreja Católica no campo educacional do município de Cruzeiro do Sul/Acre, por meio, sobretudo, da formação oferecida pela Escola Normal, demonstrando as interações entre o privado e o público. Partimos de uma abordagem qualitativa, com a análise de fontes como ofícios, cartas e relatórios. Buscamos aporte teórico em Bezerra (2010, 2015), Gondra e Schueler (2008), Tanuri (2000), Villela (2002), Geraldo Filho (2002), Azzi (2008), Nunes (2001). O estudo, que contemplou as décadas de 1940 a 1970, apontou para uma intensa interação entre o público e o privado no referido município. Por intermédio da Escola Normal, a Igreja Católica se fez presente nas diversas instituições públicas locais, ao mesmo tempo em que o poder público se fez constante no cotidiano da Instituição.
\end{abstract}

Palavras-chave: Privado. Público. Interação. Escola Normal.

\section{INTRODUÇÃO}

Observando a história, verificamos que a Igreja Católica, desde o início da colonização brasileira, manteve uma articulação contínua com o Estado. Como aliada do Estado, no período imperial, configurou-se como uma importante instituição de defesa da ordem. Esta aliança permitiu a Igreja "se organizar por dentro do aparelho do Estado, marcando uma relação de cumplicidade que, desde então, vem sendo mantida" (GONDRA; SCHUELER, 2008, p. 58).

$\mathrm{Na}$ região acriana, o Estado enquanto poder público também buscou desempenhar uma função secundária em relação à política de formação do povo brasileiro, empurrando para a Igreja Católica tal atribuição. Nesta direção, desde o período colonial, o Estado cumpriu um papel de subsidiador das ações da Igreja Católica no que diz respeito à formação educacional da população em vez de tomar a frente de tais iniciativas. A quem interessava esta parceria? Ao Estado, que apenas auxiliava as escolas com alguns insumos, mas não as custeava completamente? Ou à Igreja, que havia encontrado o caminho livre para direcionar a formação e a educação daquela população, tornando-se a principal coadjuvante deste processo? 
Foi nesta perspectiva questionadora que surgiu a ideia deste artigo, que tem como objetivo discutir a influência da lgreja Católica no campo educacional do município de Cruzeiro do Sul/Acre, por meio, principalmente, da formação oferecida no âmbito da Escola Normal de Cruzeiro do Sul, uma instituição privada de formação docente encarregada de suprir a demanda de profissionais para atuarem nas escolas públicas do município e adjacências.

Para desenvolver esta discussão, apresentaremos os resultados de um estudo realizado sobre a Escola Normal de Cruzeiro do Sul, no qual foi possível observar que a interação entre a Igreja Católica e o Estado era muito forte no campo educacional, otimizada, especialmente, pela atuação da Escola Normal de Cruzeiro do Sul. Esta instituição, por mais de duas décadas, foi a responsável direta por formar professores para atuar nas escolas primárias da região. Mas os profissionais formados nesta Instituição não se limitavam a lecionar nas escolas primárias, se tornavam os dirigentes das escolas, ocupando os principais cargos na administração pública educacional. Assim, a Escola Normal se constituiu no berço da formação docente escolarizada, e garantiu que a Igreja Católica se fizesse presente na organização e direção de boa parte das instituições educacionais que foram postas em funcionamento no referido município, expandindo seus preceitos, dogmas e valores católicos para o setor público.

A Escola Normal de Cruzeiro do Sul, embora tenha sido implementada pela Prelazia do Alto Juruá, e dirigida oficialmente pelas freiras Dominicanas de Santa Maria Madalena, recebeu contribuições de outras instâncias, a exemplo do Departamento de Educação do Território do Acre/DEC. O Estado, por meio do DEC, colaborou na gestão financeira da Escola através do repasse de verbas para aquisição de material permanente e de consumo, na contratação de docentes e, ainda, na aquisição de material didático. Cooperou igualmente no aspecto pedagógico, por meio do oferecimento de cursos de qualificação para os professores que lecionavam na Instituição e através de orientações legais quanto ao seu funcionamento curricular e administrativo. Mesmo recebendo essas importantes intervenções, sua autonomia era garantida pela escolha da sua diretoria, atribuição da Superiora Geral da Congregação Dominicana de Santa Maria Madalena, sob a tutela da Prelazia do Alto Juruá. Será sobre estas interações da Igreja Católica com as/e nas instituições públicas do município que nos propomos a discutir no presente trabalho.

\section{ESCOLA NORMAL DE CRUZEIRO DO SUL: A PRINCIPAL VEIA DE EXPANSAO DO CATOLICISMO NA REGIÃO}

Inácio Filho (2002) afirma que a expansão do confessional católico se deu no interior do movimento de "Restauração Católica, ação de reeuropeização do catolicismo com características claramente centralizadoras e sob a autoridade papal" (2002, p. 53). Essa ação desencadeada pela Igreja Católica aconteceu a partir de meados do século XIX, porém sua repercussão no Brasil pode ser percebida no período republicano, com a separação entre Igreja e Estado. Para o autor, "é marcante a atuação da Igreja em resgatar a catolicidade brasileira, através da imigração de congregações estrangeiras e da consequente instalação de suas escolas" (INÁCIO FILHO, 2002, p. 53), baseando-se num ensino humanístico e elitista. 
Tal como ocorreu em vários espaços do Brasil, a região do Vale do Juruá' também contou com a presença dos religiosos católicos. O grupo que migrou para esta região no intuito de expandir o catolicismo tinha nacionalidade predominantemente alemã. "No ano de 1917 os religiosos espiritanos se instalaram definitivamente em Cruzeiro do Sul, tendo sua ação intensificada mais ainda a partir de 22 de maio de 1931, quando foi criada a Prelazia Nullius do Alto Juruá [...]" (BEZERRA, 2010, p. 71-72), com sede neste município.

Se percorrermos a história, veremos que as primeiras escolas normais brasileiras foram estabelecidas por iniciativas das Províncias que, após a Reforma Constitucional de 12 de agosto de 1834, receberam a incumbência de legislar sobre a instrução pública, cabendo-lhes a responsabilidade de direcionar o ensino primário e o secundário nos seus respectivos territórios (VILLELA, 2002). Nesta direção, Gondra e Schueler (2008) afirmam que o Ato Adicional atendeu demandas descentralizadoras ao redefinir "a competência em matéria de educação, atribuindo às Províncias a autonomia legislativa, ou seja, o poder de legislar, organizar e fiscalizar o ensino primário e secundário" (GONDRA; SCHUELER, 2008 , p. 34). Foi no âmbito desta política descentralizadora que as primeiras escolas de formação docente foram construídas no Brasil, corporificadas na forma de escolas normais.

Segundo Leonor Tanuri (2000), as escolas normais do império tiveram sua história marcada por um processo de rupturas e descontinuidades em seu funcionamento, mas, ainda assim, penetraram a República e se espalharam pelo país, consolidando-se como lócus adequado de formação dos professores primários. Porém, em cada contexto histórico e político, estas instituições apresentaram-se diferentemente em seus objetivos, currículo e modelo arquitetônico.

Os primeiros anos da República foram de muitas transformações e efervescência, especialmente no campo educacional, de modo que este clima de euforia pedagógica e as transformações vivenciadas pela sociedade brasileira no final do século XIX repercutiram nas escolas normais que, paulatinamente, foram construindo um currículo mais moderno e que melhor atendesse às novas demandas de formação docente (VILLELA, 2002). As inovações não atingiram somente os espaços físicos e as orientações didáticas e metodológicas dessas instituições, ao contrário, foram percebidas inclusive na própria formação oferecida.

Neste entorno, as transformações que atingiram as escolas públicas expandiramse para a rede de escolarização católica que buscou se adequar às novas orientações pedagógicas que se vivia no meio educacional. A partir da década de 1920, "a necessidade de atrair matrículas de novas alunas fez com que as religiosas procurassem obter a equiparação de seus cursos aos colégios oficiais, que eram apresentados à sociedade como padrões de ensino" (AZZI, 2008, p. 106).

De acordo com Tanuri (2000), o ensino normal no Brasil constituiu-se através de um processo de adaptação e equiparação das escolas normais particulares às escolas normais oficiais, consolidado no final da década de 1920. Assim aconteceu "no Vale do Juruá, onde a formação de professores, também, não se constituiu em prioridade no labirinto das preocupações políticas dos governantes acrianos" (BEZERRA, 2015, p. 119). Logo, a opção que se desenhou ao Estado foi dividir com o setor privado a responsabilidade de abrir e manter um curso de formação docente para prover de professores habilitados as escolas de ensino primário. 
Como era de práxis naquele contexto, no que dizia respeito à manutenção do sistema escolar, existia uma interação constante entre o Estado e o setor privado. Foi por intermédio desta interação que, no final do ano de 1946, a diretora do DEC, Maria Angélica de Castro, visitou formalmente o Instituto Santa Teresinha, e impressionou-se com a organização do ensino primário oferecido naquela Instituição que era dirigida pelas freiras Dominicanas. Ficou ainda empolgada com a espontaneidade e a criatividade evidenciada pelas alunas, que aproveitaram para fazer demonstrações de civismo para a autoridade por meio de músicas e peças teatrais.

Uma série de conversas e acordos procedera depois daquela visita, e resultaram na proposta de criação da Escola Normal Regional, no ano de 1947, voltada exclusivamente para a formação feminina e criada em anexo ao Instituto Santa Teresinha, que desde o ano de 1938 estava em funcionamento no município. A prelazia era a responsável direta pela Escola, mas contava com o subsídio financeiro e apoio legal do Estado/Território e do Município. Na distribuição das responsabilidades, o Estado deveria custear a contratação de alguns professores, a compra de material didático, tais como livros, mobiliário, etc. Quanto à prefeitura, esta fez a doação do terreno para a construção do prédio. Já a Igreja/Prelazia ficou com a atribuição de fazer o pagamento dos demais docentes, construir o espaço físico e garantir a estrutura administrativa e pedagógica necessária à implantação do Curso (BEZERRA, 2010, 2015). As freiras dominicanas ficaram com a gestão da escola.

A iniciativa de gestar uma escola de formação docente colaborou para projetar o Instituto Santa Teresinha no cenário regional nas décadas seguintes. Além disso, garantiu que a Igreja Católica se constituísse, por um longo período, na instância principal de educação formal e informal. A Prelazia do Alto Juruá evidenciou uma grande interação com as demandas locais, percebendo a prioridade que a formação para o magistério primário representava naquele entorno. A Igreja conseguiu perceber que a alfabetização da população era um ponto crucial para o avanço do seu projeto de evangelização, mas para alfabetizar fazia-se necessário formar os professores que cumpririam tal tarefa. Deste modo, a formação docente se colocou prioritária, uma vez que boa parte dos professores que lecionava nas escolas primárias da região atuava sem a formação adequada. Como exceção, citamos casos esporádicos de professores que estudavam fora do Estado.

A Escola Normal Regional, criada no contexto da Lei Orgânica do Ensino Normal, foi autorizada a funcionar em março de 1947 e reconhecida pelo Ministério da Educação e Saúde Pública/MESP pelo Decreto no 100 de 23 de julho de 1949. Do ano de sua criação até 1964, oferecia apenas a primeira modalidade do normal, ou seja, o normal regional que equivalia ao primeiro ramo do curso secundário, o ginasial. Em 1965, a partir da criação da Escola Padre Anchieta, o curso normal se expandiu e passou a oferecer também o segundo ramo da formação normal, equivalente ao secundário colegial.

A interação do privado com o público foi além da logística que garantiu a implementação da Escola Normal. Abrangeu as práticas da Instituição, demonstrando uma perfeita assimilação e interação com os ideais do estado nacionalista, voltados para o patriotismo e o nacionalismo arraigado no cotidiano das escolas públicas. Embora mantivesse seus princípios confessionais, dialogou com as principais reflexões pedagógicas que movimentavam o meio educacional, assimilou as inovações curriculares 
do momento, atualizando suas técnicas de ensino através da obtenção de materiais didáticos, métodos de ensino e recursos pedagógicos. Nessas circunstâncias,

[...] a Instituição mesclava os princípios, métodos e materiais didáticos próprios da pedagogia escolanovista com as práticas tradicionais oriundas de uma orientação humanista-católica, sobretudo no que dizia respeito às normas de conduta no ambiente escolar (BEZERRA, 2015, p. 143).

No contexto amazônico, Estado e Igreja, embora apresentassem especificidades quanto aos objetivos e às orientações educacionais, gestaram um projeto de Escola comum que, mesmo sob a direção de uma congregação católica, manteve diálogo com as diretrizes curriculares e pedagógicas provindas do Estado.

Essa interação propiciou o crescimento da Escola Normal confessional no Vale do Juruá, substituindo a esfera pública em sua função de formadora de professores primários. A Igreja Católica, ora seguindo aos princípios provindos do Estado, ora impondo suas próprias regras de funcionamento, impetrou marcas na história da educação do município de Cruzeiro do Sul e região.

\section{O ESTADO NA ESFERA PRIVADA E A ESFERA PRIVADA NO ESTADO: CONSTRUINDO INTELECTUAIS E PROFISSIONAIS ENGAJADOS COM O PROJETO CATÓLICO}

Na região do Vale do Juruá, por um longo período de tempo, a Igreja Católica conquistou um predomínio ideológico e cultural em relação a outras instituições religiosas não católicas. No que diz respeito ao campo educacional, tal predominância foi alcançada, inclusive em relação ao poder público, que desempenhou uma função secundarizada na educação da população. No campo escolar, a Igreja católica, por intermédio das suas várias congregações, investiu numa sofisticada rede de escolarização que abrangeu desde creches até os cursos superiores, a exemplo de filosofia e teologia.

Com a finalidade de expandir o credo católico, seus missionários ofereceram instrução formal, profissionalização e assistência social à população local e, dessa forma, ajudaram a constituir, neste espaço, uma cultura mesclada por características do local e do estrangeiro. Tais características são notadas na arquitetura, alimentação, linguagem e, sobretudo, na cultura escolar.

Mas foi o projeto de formação docente que intensificou a interação entre o público e o privado no município de Cruzeiro do Sul, por meio das constantes parcerias entre a Igreja Católica local e o poder público estadual e municipal. O destaque da igreja seguiu na direção de que "as freiras tiveram que interagir com a cultura local, própria de um núcleo urbano erguido por imigrantes nordestinos, seringueiros e seringalistas, brancos, índios e caboclos" (BEZERRA, 2015, p. 333), criaram orfanatos, escolas e ainda prestavam serviços de saúde à população mais pobre, distribuindo remédios e dando orientações e assessorias em assuntos diversos.

No item anterior discutimos a interação entre o Estado e a Escola/Prelazia, demonstrando que a Instituição mantinha regular correspondência com os setores competentes do Estado, remetendo informações quanto à matrícula inicial e final, relação de diplomados, números de professores e lista de aprovados nos exames de admissão. Além disso, mantinha um acervo documental de natureza legal que abarcava os registros de autorização e de funcionamento dos cursos, pareceres e normativas. No decorrer da 
década de 1960, esta interação foi intensificada por meio de um movimento nacional que otimizou a intervenção do poder público nas instituições escolares com a finalidade de fiscalizar o cumprimento das determinações decorridas da Lei 4.024/61.

Esta intervenção do poder público nas instituições educacionais pode ser sentida bem antes da publicação da Lei 4.024. Para Nunes (2001, p. 123), "a trajetória das políticas públicas de Capanema no governo Vargas revela a permanência da tradição que tornou privada a ordem pública". A Lei Orgânica do Ensino Normal incentivou a criação de escolas privadas em detrimento das públicas e colaborou para que os Estados optassem pela criação de escolas normais regionais, em detrimento das secundárias. Nessa direção, a expansão da formação docente se deu prioritariamente por meio das escolas normais de primeiro ciclo, em prejuízo de uma rede de formação docente, efetivada por meio de seus dois ciclos.

O Estado influenciou ainda no aspecto pedagógico, via oferecimento de cursos de qualificação, assessorias e orientações quanto ao funcionamento curricular e administrativo da Instituição. Embora a Escola Normal recebesse do setor público subsídios financeiros, era considerada uma escola privada, restringindo o acesso de boa parte da população que, devido à sua condição financeira, não podia estudar numa instituição daquela natureza.

A Escola recebia também verbas que chegavam até ela por meio de doações de pessoas influentes da sociedade, como políticos e empresários do Território do Acre. Essas subvenções devem ter sido motivadas pelo fato da ideia de criação da Escola Normal ter partido do poder público e, diante disso, o governador se sentia partícipe desse processo e se empenhava em vê-lo realizado. Além dessas participações, a Escola ainda receberia incentivos de outras fontes, como por exemplo: Ministério da Educação e Cultura/MEC, Prefeitura de Cruzeiro do Sul e até da Delegacia Fiscal do Tesouro Nacional do Amazonas, evidenciando que a parceria entre o privado e o público era necessária e comum naquele momento.

Apesar dessas constatações de apoio no decorrer da história da Escola Normal e do Instituto Santa Teresinha, na realidade os acordos nem sempre eram cumpridos pelo poder público. Localizamos documentos nos quais a Escola reclama, por exemplo, da não admissão pelo Governo de suas ex-alunas no quadro de funcionários ${ }^{2}$ ou da não nomeação de uma freira para ministrar as disciplinas de Ensino de Língua Portuguesa, Geografia e História do Brasil, conforme indicação da Prelazia.

Embora houvesse alguns contratempos e até mesmo algum "mal-estar" entre a Igreja/Prelazia/Escola e o governo, as subvenções que aconteciam possibilitavam o pagamento do professorado, a cobertura de despesas diversas, a vinda de professores formados em outros países para lecionarem na Escola e, também, a aquisição de materiais pedagógicos de grande utilidade, sendo possível até mesmo a construção de um prédio com estrutura física satisfatória, que só ocorreu por conta da contribuição do poder público, inclusive municipal. O local para essa construção foi doado pela Prefeitura de Cruzeiro do Sul.

Diante do exposto, ressaltamos que os esforços para que a Escola Normal possibilitasse a oferta de uma educação com qualidade e efetiva, de forma que abrangesse o maior número possível de jovens, somente foi possível devido à parceria 
com o setor público, que fez investimentos inclusive no projeto arquitetônico da Escola. Sendo a ideia da criação da Escola Normal originariamente nascida na Diretora do DEC, não se pôde prescindir do apoio dos gestores estadual e municipal, os quais foram importantes no acompanhamento, na elaboração e na execução do projeto. A participação do poder público se estendeu em outros momentos após o funcionamento da Escola, tais como em custeio, organização e execução de cerimônias de formatura, e demais acontecimentos ${ }^{3}$.

Esporadicamente, o DEC oferecia o que hoje chamamos de formação continuada para as professoras da Instituição no sentido de acompanhamento de sua prática profissional. Mas no geral, este acompanhamento era realizado pela direção da Instituição, por meio de orientaç̃̃es para atuarem em suas salas de aula, baseadas no que haviam obtido na Escola Normal. Diante disso, o questionamento que ora se segue é pertinente: Houve outros meios de aperfeiçoamento de práticas pedagógicas para as normalistas? Quem eram as pessoas que ministraram esses cursos? De onde vieram? Que formação possuíam? São questões que este estudo suscitou e que podem vislumbrar novas investigações.

O que sabemos é que o acompanhamento docente, realizado pela diretoria da Escola Normal, acontecia em encontros regulares para planejamento e orientação do currículo a ser desenvolvido. Além de provê-los, a diretoria era quem tomava à frente destas atividades, juntamente à participação de demais religiosas que atuavam como docentes na Escola Normal. Haviam outras atividades obrigatórias que as docentes tinham que participar, promovidas pelo DEC e, posteriormente, pelo Núcleo da Divisão do Ensino Médio.

Tanto as docentes da Escola Normal quanto as professoras e professores da rede pública participavam dessas atividades que eram obrigatórias, portanto, não havia uma clara distinção entre os professores que lecionavam nas escolas públicas e aqueles que lecionavam na Escola Normal de Cruzeiro do Sul. Todos tinham que participar dos cursos oferecidos pelo Estado.

Cabe destacar que uma das melhores contribuições em relação à formação docente provinha do próprio momento dos Estágios de Regência, em que as professoras recém-formadas os levavam como exemplo para sua prática profissional. Elas os socializavam e, a partir deles, outros ensaios eram elaborados e incorporados ao cotidiano pedagógico. Nesse sentido, podemos evidenciar que as aulas do Estágio de Regência foi um dos mais importantes momentos oferecidos na Escola Normal, visto que se tornaram fundamentais para apreciação em momentos coletivos de formação. Havia assim uma confiança no papel desempenhado pelas freiras dominicanas na formação do professorado local.

Esta credibilidade que a população local depositava no trabalho de formação realizado por freiras católicas pode ser percebido em outras regiões do país, como demonstra Oliveira (2009) em seu estudo sobre o Colégio Santa Teresa em Ituiutaba/MG. De acordo com a autora, "as famílias depositaram confiança não só no ensino ministrado pelo Colégio, mas também nas decisões por elas tomadas" (2008, p. 183), e, "trabalhando com alunas internas, que posteriormente poderiam se despertar para a missão da Congregação", as irmãs solidificavam, "cada vez mais, a fé católica na cidade" (OLIVEIRA, 2008, p. 183). 
Em Cruzeiro do Sul, na história da Escola Normal, o processo de formação de professores teve dois momentos. O primeiro, de iniciativa religiosa, a Escola atendia aos anseios e preceitos da Igreja, devendo submissão a esta, mesmo contando com os subsídios do Estado. O segundo momento se deu durante a década de $1960 \mathrm{com}$ a promulgação da Lei de Diretrizes e Bases da Educação, no 4.024/61, em que a política de formação de professores passou a ser determinada pelo governo federal, com orientações de homogeneização, sobretudo das práticas educacionais para todos os docentes do território nacional. O que acarretou no controle federal sobre toda e qualquer instituição educacional, seja ela pública, privada ou confessional.

A direção da Escola Normal de Cruzeiro do Sul, juntamente à Prelazia do Alto Juruá, não mediu esforços para que em meio às dificuldades vivenciadas na fase inicial de sua implantação, o empenho de suas pioneiras não ficasse somente na lembrança, mas se concretizasse por meio de várias ações que culminaram na expansão dos cursos e vagas disponibilizadas pela Instituição. Até por volta de 1964, a oferta era somente para o primeiro ciclo do normal e, a partir de 1965, já com o nome de Escola Normal Padre Anchieta, o segundo ciclo do normal secundário começou a ser ofertado. A ampliação da formação se deu em decorrência da publicação, em âmbito nacional, da Lei 4.024/61, como já dito anteriormente, sendo esta a primeira Lei de Diretrizes e Bases da Educação, posteriormente alterada pela Lei 5.692/71.

Tais legislações de âmbito federal trouxeram mudanças significativas para a educação do país, visto que até então nada havia no sentido de oferecer uma educação que minimamente garantisse aspectos comuns e relevantes ao conhecimento de todos os estudantes brasileiros. Os cursos normais tiveram que ser reformatados, passando por um processo de readequação curricular em seus aspectos pedagógicos e didáticos, de acordo com as determinações da legislação vigente.

Mesmo com tais imposições legais, a Igreja Católica continuou influenciando fortemente na formação de jovens normalistas, oferecendo professoras com o viés formativo religioso e moralista adquirido na educação transmitida nas diversas instituições que funcionavam na região, a exemplo da Escola Normal e do Instituto Santa Teresinha, mas não somente por meio destas. Anteriormente a este momento de mudanças na formação de professores, com as leis citadas e a fim de atender a demanda masculina por educação, a Igreja Católica criou o Instituto São José que, segundo Bezerra (2015),

[...] funcionava como internato, voltado aos jovens que demonstrassem vocação para o sacerdócio. Este estabelecimento fez parte das obras da Prelazia do Alto Juruá, fundada e inaugurada em 1948, pelo Bispo Dom José Hascher. Funcionou inicialmente como Seminário Menor no mesmo prédio em que, posteriormente, foram instaladas as oficinas de aprendizagem (BEZERRA, 2015, p. 91-92).

O Instituto São José passou a ter convênio com a Secretaria de Educação e Cultura/SEC/AC, assim como outras instituições da Diocese de Cruzeiro do Sul, a exemplo do Jardim de Infância São Francisco, das Escolas de Educação Infantil Divina Providência e Marcelino Champagnat e das Escolas de Ensino Fundamental Padre Damião e Padre Alfredo Nuss. 
A preocupação dos religiosos não se ateve somente ao público jovem feminino em sua maioria e, posteriormente, aos jovens meninos, mas também aos seus familiares no sentido de formar-lhes profissionalmente. Assim, as classes menos favorecidas da população foram atendidas por meio das pastorais e dos cursos de aprendizagem manual. Os católicos alemães da Prelazia do Alto Juruá ofertaram cursos de profissionalização, tais como marcenaria, olaria, ferraria, etc., com o intuito de habilitar profissionais que até então eram praticamente inexistentes ou pouco habilitados naquele período.

Desta forma, os religiosos estrangeiros alemães foram os primeiros a instalar diversas oficinas profissionalizantes como de: mecânica, marcenaria, marchetaria, ferraria, olaria, dentre outras. Vários foram os profissionais ali formados que posteriormente puderam garantir sua sobrevivência a partir dessas oficinas. Obviamente a intenção maior era levar o evangelho e a doutrina católica à população por meio do projeto evangelizador da Igreja. $O$ público que se habilitava a fazer os cursos ofertados nas oficinas era o masculino, visto que para as moças a Escola Normal já era o bastante.

Os jovens que se sobressaíssem com melhor desempenho por vezes eram alocados na própria Prelazia para trabalhar em suas obras de construção de escolas, igrejas, etc. No labor diário das oficinas de aprendizagem, era comum os jovens rapazes conhecerem as jovens normalistas e, a partir daquele contato, iniciarem um relacionamento. Contudo, havia a necessidade do consentimento da Igreja e da família para que a união pudesse se concretizar. Quanto às ações sociais aos menos favorecidos, o destaque que foi encontrado evidencia a Igreja à frente de mais algumas obras, como:

A criação da Pastoral Familiar, do Conselho Indigenista Missionário/CIMI, da Comissão Pastoral da Terra/CPT, da Pastoral da Criança, do Conselho Pastoral, da Pastoral dos Idosos, da Pastoral da Saúde e do Centro de Defesa dos Direitos Humanos/CDDH. No campo social, foram construídos, entre outros, o Lar dos Idosos - Vicentinos e a Colônia dos Hansenianos Ernani Agrícola, hoje o Hospital de Dermatologia, construído onde antes existia uma pequena instalação popularmente conhecida como "Leprosário"4. Para atender aos filhos dos hansenianos, a Igreja construiu o Educandário de Cruzeiro do Sul (BEZERRA, 2015, p. 94).

Mesmo que a Igreja tenha atuado em várias frentes, sua maior contribuição foi em relação à educação escolar. Era exatamente nesse campo em que a região de Cruzeiro do Sul necessitava de maior cuidado e atenção. Os religiosos considerados como intelectuais, diante da população incauta que vivia na região, tomaram a liderança de diversas ações de cunho administrativo envolvendo a educação, saúde, assistência social e trabalho, sem, contudo, deixar de tomar os aspectos políticos sob os auspícios dos preceitos religiosos ao se envolverem em embates de interesse da população desprivilegiada socialmente. É nestas circunstâncias que Bezerra (2015) compreende estes religiosos como "[...] uma intelectualidade cunhada no chão da escola, que, embora pautando-se por objetivos confessionais, foi capaz de formar para além da fé católica e constituir importantes lideranças no campo político e cultural" (2015, p. 161).

Conforme Sirinelli (2003), podemos pensar em duas acepções para o termo intelectual, "uma ampla e sociocultural, englobando os 'criadores e mediadores' culturais, a outra mais restrita, baseada na noção de engajamento" (2003, p. 242). Na direção das colocações do autor, a primeira acepção abarca jornalistas, escritores, professores secundários, eruditos, além de parte dos estudantes, criadores ou "mediadores culturais" 
em potencial, bem como outras categorias de "receptores de cultura". A segunda acepção, porém, é "mais estreita e baseada na noção de engajamento na vida da cidade como ator, - mas segundo modalidades específicas, como por exemplo, a assinatura de manifestos" (SIRINELLI, 2003, p. 243).

$\mathrm{Na}$ condição de intelectuais, segundo esse mesmo autor, o intelectual tem pela população o apoio irrestrito e de forma privilegiada no debate da cidade, e ainda se colocando a serviço da causa que defende. Ao defender uma causa afeta aos desfavorecidos socialmente, os intelectuais agregam apoio e ganham impulso para transitarem em vários espaços sociais. Conforme aponta Sirinelli (2003), os religiosos alemães da Igreja Católica, que viveram em Cruzeiro do Sul e em toda região do Vale do Juruá, como intelectuais, apresentaram importantes contribuições para mudanças positivas no cenário que se apresentava na ocasião.

É inegável a contribuição desses religiosos que deixaram suas marcas nas pessoas que por eles foram educadas e orientadas. A interferência desses religiosos não se deu somente no campo da evangelização, compreendidos como intelectuais, operaram diversas modificações naquele contexto, interferiram em temas polêmicos de âmbito público e privado. A educação foi, a princípio, o caminho, mas que levou a outros caminhos de emancipação de uma população que carecia de quase tudo, senão de tudo!

A profissão docente obteve grande status em meio àquela sociedade, admirada e respeitada pelas famílias, tornou-se lócus quase que único de atuação de trabalho da mulher fora de casa. Valorizada a profissão de professora, esta ganhou status perante a comunidade, era prestigioso ser professora, havia o respeito de todos, que obedeciam às ordens da professora, "alunos, famílias e comunidade, principalmente quando se tratava de uma educadora formada na Escola Normal de Cruzeiro do Sul, local de onde irradiava os mestres mais renomados que atuavam no município e nas cidades vizinhas" (BEZERRA, 2015, p. 336).

A Escola Normal de Cruzeiro do Sul garantia ingresso rápido e a certeza de inserção no mercado de trabalho, de maneira que os mestres adjuntos foram perdendo seu espaço para as normalistas. Bezerra (2015, p. 336) destaca que: "Para os adjuntos restaram às escolinhas particulares ou as cadeiras públicas no meio rural, já para as normalistas, descortinavam-se muitas possibilidades". Foi do interior da Escola Normal de Cruzeiro do Sul que, por mais de três décadas, se formaram os profissionais da educação que atuaram como gestores, supervisores e professoras da região. Foi também através desta instituição que se projetou a principal intelectualidade local, emanada de uma formação moral, de cunho religioso católico.

Diante do exposto, destacamos que para as normalistas o leque de possibilidades era bem maior do que para os professores adjuntos, a depender do grau de desempenho escolar, elas poderiam lecionar no Grupo Escolar, no Instituto Santa Teresinha, nas demais escolas primárias urbanas do município ou ainda em escolas rurais. As alunas que melhor se destacassem no decorrer do curso normal, sobretudo nos momentos de estágios supervisionados, eram premiadas e tinham a primazia de lotação nos anos iniciais escolares, em especial na própria Instituição que as formou. As que se saíssem de forma mediana poderiam ser lotadas em outras escolas de menor destaque e até mesmo no interior do município, nos seringais. As pessoas formadas pelas escolas da Igreja Católica 
estavam inseridas nas diversas instituições públicas do município, ocupando cargos de chefia ou desempenhando o magistério.

\section{CONSIDERAÇÕES FINAIS}

Quanto à relação entre o público e o privado no que se refere à educação no Acre, especificamente no município de Cruzeiro do Sul, constatamos que a Igreja Católica teve um papel fundamental em articular ações que coadunassem com essa parceria. Foi a partir dos anos de 1960 que acordos entre o DEC e a diretoria do Instituto Santa Teresinha se firmaram com mais solidez para a contratação e o pagamento de boa parte dos professores que atuava no Instituto Santa Teresinha e na Escola Normal, e para a aquisição de materiais de apoio ao ensino.

Estes acordos financeiros e pedagógicos passaram a garantir a presença do Estado na administração desta rede de escolarização privada no município de Cruzeiro do Sul. Porém, a lgreja não deixou de se fazer bem presente na esfera pública por meio da formação dos profissionais que iriam atuar nas escolas públicas.

Os católicos religiosos foram durante várias décadas os responsáveis por gestar, supervisionar e, principalmente, formar professoras e professores. Além das mulheres atuarem como professoras, posteriormente também atuaram como funcionárias em bancos, comércios, repartições públicas e em diversos cargos administrativos. Homens e mulheres se tornaram políticos, sindicalistas e intelectuais que tiveram à sua frente exemplos de formadores.

Como já mencionado, os católicos alemães atuaram de forma bastante ampla no cenário cruzeirense. Atuaram na educação, na política, na economia e, em especial, na cultura. Produziram materiais pedagógicos, didáticos e formularam orientações curriculares a serem adotadas pelas instituições que funcionavam na região, principalmente na Escola Normal e Instituto Santa Teresinha, além de intervirem nas práticas pedagógicas, na gestão de instituições públicas e particulares.

Além da formação propriamente escolar, oferecida por meio das diversas escolas colocadas em funcionamento no município de Cruzeiro do Sul e região, a exemplo da Escola Normal, ofertaram ainda oficinas para a preparação para o trabalho, sendo caracterizada como educação informal. Os ofícios manuais se fizeram presentes por meio das oficinas de aprendizagem da Diocese. Neste caso, sobressaiu o grupo de religiosos que arquitetaram e construíram prédios monumentais no Vale do Juruá e, ainda, ensinaram à juventude ofícios artesanais. No campo social atuaram como ações caritativas oferecendo atendimento aos doentes, prestando orientações de saúde pública.

Auxílio financeiro foi articulado pela Igreja Católica para o Juruá, por intermédio da articulação desta com o Estado e com a prefeitura municipal, de onde proveio parte das verbas necessárias à construção do prédio do Instituto Santa Teresinha. Isso denota as relações estreitas verificadas na presença do poder público durante os exames e estágios desenvolvidos na Escola Normal.

Tanto a Igreja quanto o poder público se beneficiavam mutuamente por meio das parcerias que eram estabelecidas. A Igreja conquistava mais fiéis para suas obras e o poder público avançava em seu projeto de progresso da região. As escolas foram criadas e ampliadas e a religião católica também angariou adeptos... 
Assim, finalizamos nossa reflexão, afirmando que no município de Cruzeiro do Sul e em todos os demais municípios da região do Vale do Juruá, a rede de escolarização criada pela Igreja Católica, por meio da Prelazia do Alto Juruá desempenhou um papel importante na formação da população local e possibilitou intercâmbios entre o poder público e o setor privado confessional. Estes intercâmbios se fizeram por meio da presença pedagógica e financeira do Estado nas escolas da Igreja Católica, especialmente no Instituto Santa Teresinha e na Escola Normal de Cruzeiro do Sul. Mas se fizeram também por meio da presença da Igreja e dos seus valores religiosos nas instituições públicas do município, uma vez que os profissionais formados pelas escolas católicas atuaram como gestores, supervisores e professores no setor público e nestes espaços transmitiam a fé católica e os valores cristãos emanados do catolicismo de vertente alemã.

Artigo recebido em: 09/01/2019 Aprovado para publicação em: 08/03/2019

\section{THE CATHOLIC CHURCH INFLUENCE ON THE EDUCATIONAL SUBJECT IN THE CITY OF CRUZEIRO DO SUL/ACRE: REFLEXIONS ABOUT THE INTERACTION BETWEEN PUBLIC AND PRIVATE}

ABSTRACT: This study aims to discuss the influence of the Catholic Church in the educational field in the city of Cruzeiro do Sul, located in Acre, an state of Brazil, though, above all, the training offered by the Normal School, demonstrating the interactions between the private and the public teaching. We start from a qualitative approach, through the analysis of sources such as letters, letters and reports. We seek theoretical input in Bezerra (2010, 2015), Gondra and Schueler (2008), Tanuri (2000), Villela (2002), Geraldo Filho (2002), Azzi (2008) and Nunes (2001). The study he contemplated from the 1940s to the 1970s pointed to an intense interaction between the public and the private teaching in that municipality. Through the Normal School the Catholic Church became present in the various local public institutions, while the public power became constant in the daily life of the Institution.

KEYWORDS: Private teaching. Public teaching. Exchanges. Normal School.

\section{EL INFLUJO DE LA IGLESIA CATÓLICA En EL CAMPO EDUCACIONAL DE LA CIUDAD DE CRUZEIRO DO} SUL/ACRE: REFLEXIONES SOBRE LA INTERACCIÓN ENTRE EL PÚBLICO Y EL PRIVADO

RESUMEN: Este estudio tiene por objetivo discutir el influjo de la Iglesia Católica en el campo educacional en la ciudad de Cruzeiro do Sul/Acre, a traves, sobretodo de la formación ofrecida por la Escuela Normal, demostrando las interacciones entre el privado y el público. Empezamos de un abordaje cualitativa, por medio de análisis de fuentes como ofícios, cartas y relatórios. Buscamos aporte teórico en Bezerra (2010, 2015), Gondra y Schueler (2008), Tanuri (2000), Villela (2002), Geraldo Filho (2002), Azzi (2008), Nunes (2001). El estudio que abordó las décadas de 1940 hasta 1970 apontó para una intensa interacción entre el público y el privado en la dicha ciudad. Por intermedio de la Escuela Normal la Iglesia Católica se hizo presente en las diversas instituciones pu 
BEZERRA, M. I. S.; GROTTI, G. L.

blicas locales, al mismo tiempo en que el poder público se hizo constante en el cotidiano de la institución.

PALABRAS CLAVE: Privado. Público. Intercambios. Escuela Normal.

\section{NOTAS}

1) Região do Estado do Acre banhada pelo Rio Juruá, hoje composta pelos municípios de Cruzeiro do Sul, Mâncio Lima, Marechal Thaumaturgo, Porto Walter, Rodrigues Alves, Feijó, Tarauacá e Jordão. Esta região no início da formação do Estado ganhou o nome de Departamento do Alto Juruá e tinha como sede o município de Cruzeiro do Sul.

2) Ofício de 26 de setembro de 1951, encaminhado pela Prelazia do Alto Juruá ao DEC/Ac e Ofício do DEC/Ac, de 28 de fevereiro de 1969.

3) Jornal o Regate de $1^{\circ}$ de janeiro de 1951.

4) Denominação popular para o abrigo de pessoas com hanseníase; construído e dirigido pela Igreja Católica, no município de Cruzeiro do Sul.

\section{REFERÊNCIAS}

AZZI, R. A Igreja Católica na formação da sociedade brasileira. Aparecida, SP: Santuário, 2008.

BEZERRA, M. I. A Escola normal regional de Cruzeiro do Sul: tecendo memórias e histórias sobre a formação religiosa católica alemã na Amazônia acriana (1947-1965). 2010. 248 f. Dissertação (Mestrado em Educação) - Faculdade de Educação, Universidade Federal Fluminense, Rio de Janeiro, 2010.

BEZERRA, M. I. Formação docente institucionalizada na Amazônia acriana: da Escola Normal Regional à Escola Normal Padre Anchieta (1940-1970). 2015. 410 f. Tese (Doutorado em Educação). - Faculdade de Educação, Universidade Federal Fluminense, Rio de Janeiro, 2015.

BRASIL. Lei de Diretrizes e Bases da Educação. Lei n 4.024 de 20 de dezembro, 1961.

GONDRA, J. G.; SCHUELER, A. Educação, poder, sociedade no império brasileiro. São Paulo: Cortez, 2008.

INÁCIO FILHO, G. Escolas para mulheres no Triângulo Mineiro (1880-1960). In: ARAÚJO, José Carlos Souza; GATTI JUNIOR, Décio (Org.). Novos temas em história da educação brasileira: instituições escolares e educação na imprensa. Campinas, SP: Autores Associados/EDUFU, 2002. p. 39-64. 
NUNES, C. As políticas públicas de educação de Gustavo Capanema no governo de Vargas. In: BOMENY, H. (Org.) Constelação Capanema: intelectuais e política. Rio de Janeiro. Ed. FGV, 2001. p. 103-125.

OLIVEIRA, Lúcia Helena. Entre a memória e o arquivo: o Colégio Santa Teresa de Ituiutaba. In: SOUZA, Sauloéber, Társio de; RIBEIRO, Betânia de Oliveira Laterza (Org.). Do público ao privado, do confessional ao laico: a história das instituições escolares na Ituiutaba do século XX. Uberlândia: EDUFU, 2009. p. 177-208.

SIRINELLI, F. Os intelectuais. In: REMOND, R. (Org.). Por uma história política. Rio de Janeiro: Ed UFRJ/FGV, 2003. p. 231-270.

TANURI, L. M. História da formação de professores. Revista Brasileira de Educação. Rio de Janeiro, n.14, p. 61-88, maio/jun./ago. 2000.

VILLELA, H. O mestre-escola e a professora. In: LOPES, Eliane Marta Teixeira et al. 500 anos de educação no Brasil. 2. ed. Belo Horizonte: Autêntica, 2002. p. 95-134.

Maria Irinilda da Silva BezerRa: Professora do Centro de Educação e Letras, do Campus Floresta, Curso de Pedagogia. Atua na área de História da Educação e Ensino de História. ORCID: https://orcid.org/0000-0002-2572-414X

E-mail: irinilda@bol.com.br

Giane LucÉlIA Grotti: Doutora em Educação pelo Programa de Pós-Graduação em Educação pela Universidade Federal do Paraná /UFPR. Professora Adjunta do Centro de Educação, Letras e Artes/ Curso de Pedagogia da Universidade Federal do Acre/UFAC. Atua na área de Infância: História da Infância: Assistência a criança pobre no Acre; Educação Infantil.

ORCID: https://orcid.org/0000-0002-1743-5276

E-mail: sianegrotti@uol.com.br

Este periódico utiliza a licença Creative Commons Attribution 3.0, para periódicos de acesso aberto (Open Archives Iniciative - OAI). 